\title{
El juego del cornerball, un pre-texto del pasado para crear debate en la educación física del presente \\ The game of Cornerball, a pre-text of the past to create debate in the physical education of the present \\ *Jordi Brasó Rius, **Xavier Torrebadella Flix \\ *Universidad de Barcelona (España), **Universidad Autónoma de Barcelona (España)
}

Resumen: Comúnmente, la enseñanza de la educación física moderna ha permanecido asociada al mito de la renovación pedagógica. Sobre este supuesto presentamos, a modo de ejemplo, un inédito suceso histórico que visibiliza las contradicciones profundas de la educación física contemporánea. Sobre el análisis sociogenético inferimos una crítica a la enseñanza actual de la educación física para que se despoje de los dispositivos subyacentes que aún siguen modelando y sujetando las conciencias del alumnado privándole de la emancipación personal y ciudadana. Este es el objetivo del presente artículo. A partir de una metodología centrada en el análisis de fuentes documentales del s. XIX e inicios del s. XX en torno al juego -y poniendo como ejemplo la práctica lúdica del cornerball-y la educación física escolar, juntamente con el estudio de las principales obras de pedagogía crítica actuales, sugerimos la invención de una Educación Física diferente a través de didácticas reflexivas de la emancipación. Una de estas didácticas puede ser la que hemos llamado complicidades democráticas de resistencia (CDR).

Palabras clave: cornerball, educación física, Institución Libre de Enseñanza, Instituto-Escuela, juegos escolares, género, pedagogía crítica.

\begin{abstract}
Commonly, teaching of modern physical education has remained associated with the myth of pedagogical renewal. On this assumption we present, as an example, an unprecedented historical event that visualize the profound contradictions of contemporary physical education. Using sociogenetic analysis, we present a critique of the current teaching in physical education so for it to dispose of the underlying mechanisms that keep molding and restraining students' consciences, depriving them of personal and social emancipation. This is the objective of this article. Based on a methodology centered on the analysis of documentary sources from the 19th century and the beginning of the twentieth century focusing on games - using the practice of the cornerball game as an example-and school physical Education, along with the study of the current main works on critical pedagogy, we suggest the building of a different physical education through reflective didactics of emancipation. One of these didactics may be what we call the Democratic complicity of resistance (CDR). Keywords: cornerball, physical education, Institución Libre de Enseñanza, Instituto-Escuela, School games, gender, critical pedagogy.
\end{abstract}

\section{Introducción}

Desde principios del siglo XX, la educación física siempre ha permanecido asociada al mito de la renovación pedagógica. Sin embargo, a este supuesto caben posibles objeciones que pudieran negar cualquier relación con una idea de cambio e incluso de progreso democrático. Es precisamente en la escuela el lugar donde se apuntala la permisible teoría de la reproducción social (Althusser, 2005; Bourdieu \& Passeron, 1996). En este paradigma, la educación física ha jugado históricamente un papel más que destacable y, no siempre, ha contribuido a la formación de una ciudadanía emancipada de los condicionamientos sociales y gobernantes políticos (Gambarotta \& Galak, 2012).

De este modo, la idea de una renovación pedagógica debería ser revisada en profundidad. Como han detallado últimamente los profesores Joan Soler y Conrad Vilanou (2018), en este concepto se han incorporado un conjunto de experiencias educativas de diversa índole, en ocasiones, diametralmente divergentes, pero que, por un interés u otro, se han subscrito a los relatos de la educación moderna. Si bien todos los modelos subscritos en el entorno de la llamada Escuela Nueva o Escuela Activa suponían una renovación pedagógica, por cuanto tenían en común aspectos que marcaban diferencias con los llamados métodos tradicionales, un elemento irrenunciable de esta nueva educación se en-

\footnotetext{
Fecha recepción: 27-11-18. Fecha de aceptación: 01-08-19 Daniel de la Cruz Manjón Pozas
}

dmanjonp@uoc.edu contraba en la incorporación de la educación física. No obstante, la incorporación de esta materia en la enseñanza, por sí sola, no debería ser reconocida como elemento diferencial de la renovación pedagógica - del mismo modo que una nueva metodología no puede tener suficiente fuerza pedagógica para poder declarar que un modelo es renovador-.

El presente artículo tiene una naturaleza híbrida. Por un lado, el objetivo pretende hacer una indagación histórica de la presencia del juego en la educación física escolar de principios del siglo pasado en España; por el otro, pretende aportar una visión reflexiva y crítica de la educación física en el momento actual. A partir de esta intención, se presenta el juego del cornerball; un juego de origen angloamericano que sirve como excusa para reflexionar sobre la importancia de las actividades lúdicas en la educación física escolar. Con ello, aparte de abordar la entrada de este juego en España y la importancia que tuvo en su época en el ambiente de la renovación pedagógica moderna y de la renovación de la educación física escolar, se desea también advertir sobre el rumbo que está tomando la educación física, en tiempos de las incertidumbres que surgen en la precipitación de la modernidad líquida (Bauman, 2017) y en un momento de pedagogías nombradas postmodernas (Enkvist, 2016). Por todo ello, la metodología se centra en el análisis de fuentes documentales en torno al juego en la edad escolar de principios del siglo XX, pero también, en la interpretación de un conjunto de obras relacionadas con una nueva pedagogía crítica, alejada de unos poderes dominantes que no pretenden, en ningún caso, una emancipación individual.

Hoy la incertidumbre de la educación física escolar es más que evidenciable, y no justifica esas necesidades que 
en tiempos pretéritos demandaban aquellos «primeros apóstoles» que lucharon por legitimar y dignificar la asignatura (Torrebadella, 2014b). Las dudas continúan, las posiciones y las tendencias siguen mostrando espurios defensores del deporte y de la motricidad... aferrados en el currículo seguimos con lo prescrito, cumpliendo con el orden de la ley vigente y manteniendo, como guardianes, la tradición de los códigos disciplinares que configuraron una materia escolar (Cuesta, 2002) -y guardianes del estado en la idea de controlar el sistema educativo (Chomsky, 2005)-. Así, ante una tradición o renovación se publicitan y exageran las innovaciones didácticas, las nuevas tecnologías, el aprendizaje por servicios-ApS-, la autoevaluación, la lengua inglesa como símbolo de comunicación internacional, el trabajo cooperativo y hasta un pensamiento que dicen que es crítico -cuando es de todo menos crítico-, junto a otras muchas más ilusiones pedagógicas hacía el cambio. Todo ello se nos presenta como la panacea, como un axioma de una revolución pedagógica, que no deja de ser el mantra idealista de siempre. Es más, no hacer apología de estas nuevas tendencias significa, automáticamente, ser un clásico, un tradicional o un retrógrado (Fernández Liria, García Fernández \& Galindo Fernández, 2017).

Pero quizá la pregunta real que hay que hacerse es: ¿dónde están los cambios ideológicos o, los cambios hacia el empoderamiento de la libertad de expresión...? Alguien es capaz de saber si: ¿Continuamos educando para el trabajo?, $¿$ Continuamos educando para hacer defensores de la patria?, ¿Continuamos educando para robustecer los cuerpos y regenerar la raza? ¿Continuamos haciendo al hombre más hombre y a la mujer más femenina? O simplemente ¿Educa la escuela en un ambiente de no-esfuerzo, no-fracaso, no-éxito, no-contenido?

Así pues, a partir de lo expuesto, el artículo se desarrolla entre la recuperación histórica de los acontecimientos a través del cotejo de las fuentes documentales primarias y su relación hermenéutica con los estudios recientes. Sobre esta episteme dada inferimos una correspondencia que hace de la reflexión la adopción de un pensamiento crítico de resistencia. Es sobre esta cuestión que coincidimos y concluimos con Raimundo Cuesta (2003, 2006, 2007) la idea que es todavía necesaria una crítica histórica de la escolarización de masas. $Y$ es que:

El secreto de la enseñanza escolarizada se aloja en la impenetrable caja negra que constituyen las disciplinas. Ese conocimiento en el que nos hicimos como alumnos y ahora nos hacemos como profesores contiene, como encriptadas en él, muchas de las claves de la producción y distribución de la cultura de ayer y de hoy (Cuesta, 2007, p. 17).

\section{Enfoque histórico preliminar}

A lo largo del proceso institucional de la educación física escolar iniciado a principios del siglo XIX y que hemos establecido a partir del hito histórico del Real Instituto Militar Pestalozziano (Madrid, 1806-1808), el recorrido de la educación física ha representado uno de los principales retos de la sociedad moderna. En España, ya desde entonces, los juegos corporales estuvieron presentes siguiendo el modelo prusiano de Guts-Muths, que a través de la obra La Gimnás- tica o escuela de la Juventud (Amar \& Jauffret, 1807) extendió los dispositivos o códigos disciplinares que con el tiempo fueron configurando una nueva materia educativa llamada gimnástica y, más tarde, educación física (Ayala \& Zalagaz, 2016; Llorens \& Torrebadella, 2017). No obstante, es conocido que sobre estos juegos se imprimió un espíritu militar (Mosse, 2000), que posteriormente sirvieron a Jahn para inocular un espíritu patriótico y nacional, a la sazón, contribuyendo a la reunificación de la nacionalidad alemana (Mosse, 2005). En el caso de Francisco Amorós en Francia, su desarrollo sirvió para expandir otras distintas manifestaciones apartadas de lo puramente militar y nacional. La gimnástica de Amorós también dio entrada a otros tipos de gimnásticas: atlética, higiénica, recreativa, médica y ortopédica. No obstante, fueron los ejercicios atléticos y de endurecimiento que se desarrollaban en un variado surtido de aparatos los que identificaron el sistema gimnástico de este gimnasiarca valenciano. Los ejercicios realizados en las anillas, en el trapecio, en las barras paralelas o el caballo de saltos tenían el riesgo inherente a la práctica y los golpes y caídas podían comportar una lesión duradera e incluso irreparable. De aquí el frecuente temor y las suspicacias de los padres y madres ante la gimnástica de este tipo. Si bien hay que señalar que en algunos casos la gimnástica bien dirigida tenía efectos terapéuticos y contribuía a la recuperación de la salud, en otros casos, podía tener consecuencias funestas. Los juegos gimnásticos y la gimnástica de aparatos pronto fueron reemplazados por la metodización de los ejercicios automatizados y descompuestos de una llamada gimnasia de sala sin aparatos, higiénica y racional (Torrebadella, 2014a; VicentePedraz \& Brozas-Polo, 2017). Así se ejercía un control absoluto sobre el alumnado con la técnica del orden y la disciplina que, además de controlar a un gran número de personas, se alejaba de todo riesgo de accidentes.

Al llegar a principios del siglo XX, el éxito internacional que tenía el sistema de gimnástica sueco puso las bases de la escolarización de la educación física, sin aparatos, como ya se venía haciendo con la gimnasia de sala. Así, gracias a esta metodología, se podía ejercitar a un nuevo alumnado, al unísono y en masa. A la vez, venía a representar un buen recurso para continuar amaestrando las voluntades de los alumnos y advertirles, simbólicamente con este tipo de ejercicios, que el orden, la disciplina y la obediencia a las normas eran los valores más fundamentales para servir a la sociedad. Obviamente, la incorporación de la gimnástica sueca coincidió con las necesidades de disciplinar -acaso nacionalizara grandes masas, como así era de menester para intervenir en una asignatura de ejercicios corporales que se presentaba por primera vez -y con mucho retraso- para escolarizar a la población obrera (Torrebadella, 2013b). Además, por otro lado, había una intención de atender las exigencias de un servicio militar obligatorio (Torrebadella-Flix, 2016). Se buscaban, por lo tanto, recursos fáciles para adiestrar y adoctrinar en la sumisión, obediencia, disciplina al trabajo y sacrificio a una población que nacía condenada a ocupar el puesto social que a cada uno le correspondía (Torrebadella-Flix \& Brasó, 2017).

Hay que detallar que, en este contexto, la educación quedaba relegada a una generalizada indiferencia del profesorado y a la desatención administrativa. Y ello se agravaba con 
unos elevados índices de absentismo escolar, por un lado, pero también por la falta de escuelas para atender a toda la población. En este contexto, las niñas eran las más perjudicadas, la educación de la mujer en España estaba en un completo abandono y, más aún, cuando se trataba de su educación física. De aquí que se indicase que el mejor ejercicio que tenían las niñas eran los juegos de corro (Pulido, 1906).

Pero la realidad en los colegios privados -los de las congregaciones religiosas- era bien distinta. Aunque también se introdujo la gimnasia sueca, pronto fueron receptivos a incorporar los llamados juegos corporales al aire libre, especialmente el fútbol (Torrebadella-Flix \& Vicente-Pedraz, 2017), además de otras actividades gimnásticas y atléticas para imprimir energía y virilidad al cuerpo. No sucedía así en los colegios de niñas, en donde la gimnasia sueca, si bien se complementaba con algunas recreaciones, era fundamentalmente el poco ejercicio o movimientos que se hacía, a veces al ritmo de un piano.

\section{La educación física, los juegos y los deportes en el Ins- tituto-Escuela}

A principios del siglo $\mathrm{XX}$ ante el descontento por la enseñanza pública se movilizó en Madrid la creación de la Asociación de Profesores Racionalistas (1909-1919) y, más tarde, en 1912, la Asociación General de Magisterio, vinculada a la Unión General de Trabajadores (De Luis, 2006). Esto sucedía en un momento crítico cuyo punto álgido se alcanzaba con el enfrentamiento ideológico entre las tesis integristas del nacionalcatolicismo del Padre Andrés Manjón (1910) y los defensores de la libertad de pensamiento. Entre estos, la Institución Libre de Enseñanza (ILE) lideraba la representación del liberalismo pedagógico y la reafirmación política de una escuela neutra en cuanto a la enseñanza religiosa (De Puelles, 2017).

Por otro lado, después de oficializar en 1901 a regañadientes la educación pública y obligatoria de los 6 a los 12 años, hay que señalar la precaria situación de la enseñanza pública, con presupuestos insuficientes y sin apenas una clara voluntad política de afrontar el problema social de la escolarización (De Puelles, 2017). Asimismo, en el escenario de la Primera Guerra Mundial, los países del bando aliado como Francia e Inglaterra veían la necesidad de vigorizar la raza y de aquí surgía la idea de reformar los estudios de segunda enseñanza. Por ejemplo, en Francia, en la adolescencia-de los 13 a los 17 años-, la educación física masculina era militarizada-con ejercicios de tiro y preparación militar-. Además, para el sexo femenino se proveía de una preparación maternal a las mujeres. Y en Inglaterra, se proyectaba la instalación de campos de juegos deportivos en todas las escuelas para potenciar la educación física del alumnado (Luzuriaga, 1917, 1918a).

Sobre este contexto reformista surgió el Instituto-Escuela de Madrid, creado por iniciativa de la ILE y por el Decreto de 10 de mayo de 1918, del ministro Santiago Alba. La finalidad de este centro era la de ensayar nuevos métodos dirigidos hacia una futura reforma de los estudios de Bachillerato.

Inicialmente, el Instituto-Escuela se emplazó en un lujoso edificio de la calle Miguel Ángel $n^{\circ}$ 8, que pertenecía al
International Institute for Girls fundado en España por Alice Gulick (Vázquez Ramil, 2012) ${ }^{1}$. El proyecto fue dirigido y coordinado por la Junta de Ampliación de Estudios Científicos. A pesar de los muchos ataques del conservadurismo católico y de otros contratiempos, el Instituto-Escuela consiguió ser una realidad (Ontañón, 1988; Palacios Bañuelos, 1988; Ramírez Aisa, 1994).

Así pues, esta institución fue una magnífica oportunidad para ensayar los métodos educativos en boga y valorar las experiencias didácticas. En primer lugar, hay que señalar que en este centro se proponía un modelo de coeducación y un acercamiento a la psicología educativa, implantando toda la corriente de innovación de las escuelas democráticas más representativas del momento y, en este punto hay que destacar su especial interés por la educación física (Martínez Navarro, 1988). La asignatura de educación física-juegostenía la atención de una hora al día. Los juegos, las excursiones, las danzas, la gimnástica rítmica y los deportes aparecían regularmente. Entre los deportes se practicaron el fútbol, el tenis, el baloncesto y, otros tantos, de origen norteamericano -dodgeball, baseball, croquet, cornerball y volleyball-, que fueron a cargo de las maestras Miss Nora Sweeny y Miss Marion Selden. Estas maestras estaban pagadas por el International Institute for Girls y su misión era el colaborar en el desarrollo de la educación de la mujer en España. Lo que hacían era impartir la enseñanza del inglés y de los juegos, además de atender la educación general del Instituto-Escuela, en colaboración con el profesorado español -es evidente el símil con la introducción del fútbol en Alemania y que se recoge en la película Unidos por un sueño (2011)-. En cuanto a los juegos de niños, el maestro era Jacobo Orellana Garrido, que también se encargó del programa de excursiones (Junta Ampliación de Estudios, 1922).

Hay que destacar, además, que en este momento se introdujo el tratado de la profesora Ketty Jentzer, Juegos educativos al aire libre y en casa (1921), una traducción del profesor Jacobo Orellana. Esta obra fue una excelente guía de juegos que aportó oxígeno a la educación física escolar y a la introducción de muchos juegos completamente desconocidos por los maestros y maestras españoles. Iba además en la línea de toda una idea higiénica de renovación y de movimiento escolar que Eleizegui (1925) ya impulsó (Brasó, 2018b). A modo de ejemplo, Orellana ya destacaba que:

Preocupación constante ha sido para nosotros contrarrestar los perniciosos efectos de la prolongada quietud a que se tienen sometidos en muchas escuelas a los alumnos, motivada unas veces por las pésimas condiciones de los edificios, faltos de patios, jardines o campos de juego, y otras por el equivocado concepto de autoridades y padres ignorantes, que creen ver en los paseos y juegos escolares un motivo de distracción de sus deberes para los maestros y un tiempo perdido para la educación de los niños...

Afortunadamente se va perdiendo ese prejuicio, y los juegos y excursiones van ocupando el lugar preferente que siempre debieron tener en los programas escolares. (...)

El libro de la señorita Jentzer facilitará indudablemente la tarea a los maestros que se interesen en esta fase importante de la educación (Orellana, prólogo en Jentzer, 1921, p. 9-11). 
Ketty Jentzer colaboraba en el Instituto Jean Jacques Rousseau de Ginebra, creado por Édouard Claparède en 1912. Se trataba de una escuela de ciencias de la educación, de la cual se impulsaron iniciativas de renovación pedagógica, que trascendieron internacionalmente como métodos de la «escuela activa». Junto a la concepción educativa de Claparède, para el profesor Joan Soler i Mata (2009, 2016) son destacables también las influencias de Adolfo Ferrière (1879-1860), Georg Kerschensteiner (1854-1932) y John Dewey (1859-1952).

La ILE, ensayó a partir del Instituto-Escuela un modelo angloamericano de educación física fundamentado en los deportes. Como citaba ya el mismo Rufino Blanco, en este asunto no había controversia:

Los mejores juegos corporales son los que se practican al aire libre, y si el fin de la educación es formar hombres libres que sepan hacer buen uso de su libertad, ningún ejercicio puede contribuir tanto a este fin como el de los juegos corporales (Blanco, 1919, p. 21).

Por su parte, Lorenzo Luzuriaga (1919), representante de la ILE, pedía que, para atender las exigencias de la pedagogía moderna, las grandes ciudades construyesen jardines y campos de juegos para niños. Ponía como ejemplo las iniciativas tomadas por el gobierno de la Mancomunidad de Catalunya y el Ayuntamiento de Barcelona, cuya Comisión de Cultura había puesto en marcha el proyecto de «jardines escolares», sin precedente en el territorio español. La cooperación de los trabajos realizados por la Junta de Protección a la Infancia y el Ateneo Enciclopédico Popular había culminado con una partida inicial 70.000 pesetas aprobadas en el presupuesto de 1918 (Ajuntament de Barcelona, 1920).

Asimismo, en la memoria de la Junta Ampliación de Estudios e Investigaciones Científicas (1922), se mencionaba el siguiente resumen de los juegos en el Instituto-Escuela, durante el curso 1920-1921:

La Sección preparatoria dedicó una hora diaria a juegos. Colaboraron en ellos las profesoras norteamericanas del Instituto Internacional.

Estas mismas profesoras dirigieron los juegos de la Sección secundaria de niñas. Introdujeron algunos de los usados en las escuelas de los Estados Unidos: dodgeball, baseball, tennis, croquet y cornerball, ejercicios gimnásticos y bailes populares; también organizaron una representación teatral en inglés y algunas fiestas.

En la Sección secundaria de niños dominó el juego de foot ball, complementado, en menor escala, por tennis, rounders y bolos. Se utilizó un campo amplio, alquilado para este fin, y contiguo a la Residencia de Estudiantes de la calle del Pinar. Los alumnos sufragaron, por suscripción, los gastos de material (Junta Ampliación de Estudios, 1922, p. 264-265).

Durante el curso 1921-1922 prácticamente se siguió la misma orientación que en el curso anterior, no obstante, esta vez, se aprecian probablemente los primeros ensayos del juego del volley ball en España, entre la población escolar (Torrebadella, 2018a):

No ha habido variación esencial con relación al curso anterior. Las niñas y niños de la Sección preparatoria fueron dirigidos por sus maestras. Las niñas de la Sección secundaria, por las dos profesoras norteamericanas, que arreglaron los juegos en una gradación de dificultad: para las niñas más jóvenes, dodge ball, volley ball y base ball, alternados con ejercicios gimnásticos, y en los meses calurosos croquet y tennis; para las de edades intermedias, base ball, tennis y algunos ejercicios gimnásticos; para las mayores, volley ball, basket ball y tennis. Las profesoras observaron que las niñas no hacen con gusto gimnasia, prefiriendo los juegos, y que en estos participan las niñas jóvenes con más afición que las mayores.

Los niños han jugado foot ball, rounders y tennis. En el mes de junio organizaron una fiesta de juegos olímpicos, que despertó gran entusiasmo entre alumnos y familias.

Ofrecido generosamente por las profesoras del Instituto Internacional de señoritas, se organizó un curso breve de juegos, danzas y gimnasia, propio para las niñas de las escuelas primarias y secundarias, con el propósito de adaptar a nuestro país algunos de los ejercicios usados en los Estados Unidos, y destinado principalmente a maestras españolas (Junta Ampliación de Estudios, 1922, p. 283-284).

Con los años, la presencia del deporte en el InstitutoEscuela fue a más. Prueba de ello es la Olimpíada escolar que se verificó en el campo de la Residencia de Estudiantes, en abril de 1924:

El Instituto-Escuela cultiva, con gran esmero, la afición por los juegos y deportes al aire libre; los alumnos alternan las clases con los recreos en el jardín, las partidas de tennis y la gimnasia sueca, y al finalizar el curso se celebra una fiesta atlética en que toman parte todos los alumnos, sin exceptuar a los párvulos y a los de la sección primaria. (De Castro, 1924, p. 200)

El modelo inspiró la creación de otros Institutos-Escuela: Barcelona, Valencia, Sevilla o Sabadell. Hay que destacar que en estos Institutos la educación física, los juegos y los deportes -fútbol, baloncesto, natación, atletismo, excursionismo o esquí- adquirieron una especial relevancia.

Por otro lado, las maestras norteamericanas Miss Nora Sweeny (1894-1979), «graduada por la Sargent School por Physical Education en 1916» (Vázquez Ramil, 2012, p. 179) y Miss Marion Selden impartieron, a cargo del International Institute for Girls y la colaboración de la Junta de Ampliación de Estudios (JAE), el que podría ser el primer curso de formación específica de educación física y juegos para maestras (Murga, 2009). La noticia del curso fue divulgada en la prensa y, también en la revista La Escuela Moderna:

Juegos y gimnasia para niñas. - Ofrecido generosamente por las profesoras del Instituto Internacional de Señoritas, se ha organizado un curso breve de juegos, danzas y gimnasia propios para las niñas de las escuelas primarias y secundarias. El curso trata de adaptar a nuestro país algunos de los ejercicios usados en los Estados Unidos, y se destina a las maestras españolas que quieran introducir esos ejercicios físicos en sus escuelas.

Las clases y las prácticas en la sección de niñas del Instituto-Escuela, serán dirigidas por Miss Marion Selden y Miss Nora Sweeney. Tendrán lugar desde el 24 de febrero al 7 de abril.

El número de maestras admisibles se limita a veinte. El curso es gratuito.

Se ha pedido a la Dirección general de Primera enseñanza que permita seguir el curso a algunas maestras de escuelas 
públicas.

Las inscripciones pueden hacerse en la Junta para Ampliación de Estudios, Almagro, 26, hotel (Juegos y gimnasia para niñas, 1922, p. 208).

Por lo tanto, la Dirección general de primera enseñanza cuyo cargo desempeñaba Fernando Suárez de Tangil y Angulo, Conde de Vallellano y segundo Marqués de Covarrubias de Leyva- asumió la organización de un «concurso breve de juegos, danzas y ejercicios gimnásticos para niñas» que se presentaba como la oportunidad de dar entrada a nuevos métodos de educación física femenina. Por eso, en la Gaceta del 12 de febrero de 1922, se publicó una Orden-11 de febrero-convocando diez plazas para maestras e inspectoras con el propósito de participar en el citado curso:

Habiendo de inaugurarse el día 8 de marzo próximo un curso breve de once lecciones de juegos, danzas y ejercicios gimnásticos, propios de niñas, organizados por las profesoras norteamericanas del Instituto Internacional para señoritas de Madrid,

Esta Dirección general, defiriendo a deseos expresados por la Junta para ampliación de estudios e investigaciones científicas, ha resuelto que las maestras propietarias de escuelas de Madrid que no excedan de treinta y cinco años de edad, y las inspectoras de Primera enseñanza en las mismas condiciones, puedan presentar solicitudes para tomar parte en el mencionado curso, en esta Dirección general, en el plazo de ocho días; entendiéndose que sólo podrán ser cubiertas diez plazas de alumnas (Tangil, 1922a, p. 198).

Días más tarde se publicó la Orden de 27 de febrero de 1922, en la Gaceta del 2 de marzo, por la que se ponía en conocimiento las dos inspectoras -Juliana Torrego Pedrazuela y Luisa Becares Mas- y cuatro maestras -María Santamaría, Remedios Pilar Ángulo y Puente, Enriqueta Lucas y Ana y Carmen del Valle y García Aranda- que habían sido escogidas para el mencionado curso de juegos, danzas y gimnasia (Tangil, 1922b).

Como podremos comprobar, este curso puso en contradicción el sistema de coeducación que inicialmente había planteado la ILE. La coeducación de entonces era la convivencia de ambos sexos en un mismo espacio educativo, pero con roles separados y prejuiciosos. La prescripción de los juegos de niñas y también los deportes tenían una asignación de género. Si los hombres podían jugar a los deportes rudos, violentos y de simulacro -de la guerra-, como eran entonces llamados el foot-ball association y al foot-ball rugby, las jóvenes tenían que iniciarse en deportes menos violentos y de menor contacto físico. Entre estos juegos y deportes fueron practicados el netball, el pushball, el voley-ball, el basket-ball, el hand-ball y el hockey (López-Villar, 2014; Sánchez-Ribera \& Torrebadella-Flix, 2018; Torrebadella-Flix, 2013a, 2014b, 2018a; Torrebadella-Flix \& Ticó, 2014; Tagg, 2016). Por consiguiente, el deporte y la educación física contribuían a fijar los roles de masculinidad y feminidad burgueses. Había que evitar pues, la afeminación del hombre, pero también, la masculinización de la mujer (Caspistegui, 2004; Scharagrodsky, Manolakis \& Gosende, 2003).

En esta línea, la ILE mantuvo la Residencia Internacional de Señoritas de Madrid (RIS, 1915-1936) ubicada en un Hotel de la calle Fortuny $n^{\circ} 28, n^{\circ} 30, y^{\circ} 53$, y el edificio de la calle
Miguel Ángel 8, propiedad también del International Institute for Girls. La RIS estuvo dirigió María de Maeztu y Whitney (1881-1948), que a su vez fue también miembro de la Junta del Instituto-Escuela y presidenta del Liceum Club femenino (1926-1939) -un cultural círculo elitista-. Los acuerdos de la JAE con el International Institute for Girls obligaron a otorgar los edificios para la enseñanza exclusiva de la mujer (Vázquez Ramil, 2012). La educación física en la RIS y en el Instituto-Escuela estuvo impartida por profesoras americanas y aparte de las ya citadas hay que añadir a Nellis McBroom, durante el curso 1927-28(Vázquez Ramil, 2012).

La actividad deportiva de estas muchachas tenía por lo tanto un modelo genuinamente estadounidense, que provenía del acuerdo con el International Institute for Girls: «a partir de 1921 las profesoras americanas se encargaron durante algunos cursos de enseñar, además de la gimnasia, juegos a las residentes; los preferidos eran el tenis y el baloncesto» (Vázquez Ramil, 2012, p. 272). Hay que destacar aquí la moderna imagen femenina propagada por Lilí Álvarez (1927), campeona del Trofeo Wimbledon de tenis en 1926, 1927 y 1928, que representó el paradigma de la nueva sportwoman europea (Vilanou, De la Arada \& Turró, 2013).

Ya en tiempos de la Segunda República, con la coyuntura social favorable que propiciaba el nuevo marco político (Pujadas, 2011), fue cuando en la RIS se constituyó un equipo de hockey y el ejercicio físico recreativo fue ampliándose y evidenciado las oportunidades de las conquistas femeninas en el deporte (García García, 2015; Justribó, 2014; López Villar, 2017; Ramos, 2017).

Entre los juegos practicados por las alumnas del InstitutoEscuela aparecía por primera vez en España el llamado cornerball, hasta entonces desconocido.

\section{El cornerball}

Este juego ya se localiza en la obra de Jessie Hubbel Bancroft (1867-1952), Games for the playground, home, school and gymnasium (1909) -en la página 359-. La autora de la obra fue directora de Educación Física en las escuelas públicas de Brooklyn y, desde 1904 hasta su jubilación, en 1928, ejerció de Subdirectora de Educación Física en las escuelas públicas de Nueva York. Fue también fundadora en 1885 de la American Association for the Advancement of Physical Education, posteriormente, en 1903, denominada American Physical Education Association (APEA).

Es curioso que desde entonces no volvemos a encontrar noticia del juego hasta que en 1932 el profesor Rafael Hernández Coronado, presidente de la Asociación de Profe-

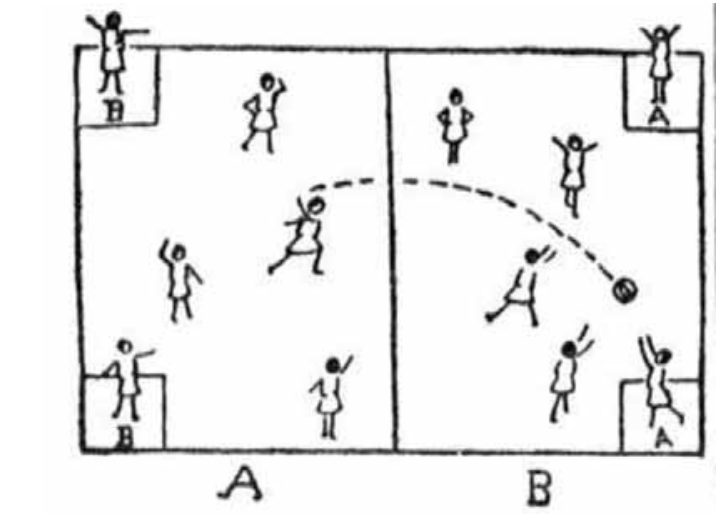

Figura 1: Imagen que completa la descripción del juego del cornerball (Hernández Coronado, 1932, p. 14) 
sores de Educación Física lo incorpora en el diario Luz.

El citado juego era descrito de manera bien concreta para que cualquier maestro o maestra lo pudiese practicar y enseñar a su alumnado. Se iniciaba con la descripción del terreno de juego, de las zonas que había que marcar, y de la disposición que los equipos tenían que ocupar:

El terreno de juego es un rectángulo dividido en dos mitades iguales por una línea que los jugadores no deberán traspasar. En cada ángulo del rectángulo se marca un cuadrado de dos metros de lado. Los jugadores se dividen en dos bandos, A y B. Cada equipo ocupa la mitad del rectángulo. Dos jugadores de A se colocan en los cuadrados del campo de B, y viceversa (Hernández Coronado, 1932, p. 14).

Posteriormente se pasaba a detallar la dinámica del juego:

El juego consiste en enviar una pelota de goma o balón de fútbol por encima de los jugadores contrarios, procurando que sea recogido por los guardianes que ocupan los cuadrados, y éstos, a su vez, enviarlo a sus compañeros que ocupan la mitad opuesta.

Si A comienza, un jugador de este campo lanza el balón por encima de los adversarios a uno de los jugadores de los cuadrados A, más los del equipo B pueden detenerlo o cogerlo sin traspasar la línea que divide los dos campos y sin introducirse en el espaciò de los cuadros, $\mathrm{y}$ a la inversa. Los guardianes de los cuadros deben coger y lanzar el balón sin salirse de ellos. Cada vez que un equipo logra que uno de sus compañeros que ocupan los cuadros se apodere del balón, obtiene un tanto. Gana el equipo que primero logra un número determinado de tantos (Hernández Coronado, 1932, p. 14).

Analizando la descripción del profesor Hernández y tratando la lógica interna del cornerball -en términos de Parlebas (2001)-, este juego está formado por un conjunto de situaciones motrices con compañeros, adversarios y en un terreno que no implica -o no tiene que implicar-incertidumbre en el medio. Asimismo, por lo que respecta al contacto con los adversarios este es mínimo, casi nulo, ya que las zonas de unos y otros están muy delimitadas y se prohíbe que cualquier equipo traspase sus zonas -por ello, el juego era óptimo para la mujer a inicios del siglo XX, según las ideas pedagógicas y principios educativos de la época (Brasó \& Collell, 2016; Brasó \& Torrebadella, 2015a). De todas formas, a diferencia de otros juegos típicos femeninos como los corros cantados, el columpio o los juegos de imitación, el cornerball destaca por su disposición-estructura del terreno a modo de juego colectivo-deportivizado, con un campo rectangular -como el fútbol, el básquet, el hoquei- y unas zonas a modo de áreas que están prohibidas por algunos jugadores -como en el balonmano o el voleibol-. Como consecuencia, el cornerball traspasa la feminidad lúdica basada en el no contacto, en la imitación y en el no movimiento, para convertirse en una práctica que está en medio de esta pasividad que tenían que tener los juegos femeninos -de modo general-, y de los deportes colectivos propiamente dichos.

\section{El pensamiento krítico y las Complicidades Democráti- cas de Resistencia (CDR)}

La división de juegos de niños y juegos de niñas ha permanecido prácticamente inalterable hasta hace pocos años. Durante varios siglos los juegos y los espacios de juegos han sido divididos por el género, ya en la calle y en la escuela (Andújar \& Brasó, 2017; Brasó \& Collell, 2016; Brasó \& Torrebadella, 2015a). A modo de ejemplo, los juegos violentos pensados para los niños han sido prohibidos a las niñas. Aun así, juegos como el del marro, considerados preferentemente de chicos, también fueron a menudo recomendados a las chicas (Brasó \& Torrebadella, 2014, 2015b, 2016). Es a partir del siglo XXI cuando se empiezan a cuestionar con claridad que las niñas puedan jugar y practicar los mismos deportes que los niños. El fútbol es un claro ejemplo que evidencia el empuje femenino, con cada vez más participantes del mal nombrado sexo débil (Brasó, 2016). ¿Era esto lo que pretendían las jóvenes profesoras misioneras de educación física norteamericanas? Claro que no; estas profesoras tenían una misión y cumplían con las complicidades educadoras de la Iglesia congregacionista-American Board of Commisioners for Foreign Missions- que tenían programadas en España (Vázquez Ramil, 2012, p. 179).

Los juegos como el cornerball y otros parecidos, inventados para la educación física de las niñas, que en su día pusieron a prueba a las maestras de las escuelas de Madrid, tenían una intención socio-pedagógica clara, construir la estética de la feminidad moderna que difundía entonces la sociedad estadounidense. Esta nueva estética de feminidad venía también a ser un revulsivo a la imagen tradicional de la mujer española. De aquí que en tiempos de la Dictadura de Primo de Rivera se intentase remodelar esta imagen proporcionando escenas paradigmáticas de la vida deportiva de las muchachas norteamericanas. La revista Armas y Deportes es un claro ejemplo de esta promoción de la figura femenina incorporando en las portadas sugerentes imágenes de cuerpos de mujeres en plena actividad física (Torrebadella, 2018b).

Sin embargo, la incorporación de la mujer española en las prácticas deportivas, no la hacía a esta más libre, como asimismo la muchacha norteamericana, no estaba más empoderada que la española. Europeizar, modernizar, progresar y desarrollarse eran, por lo tanto, sinónimos de seguir las modas extranjeras y las extravagancias del momento, eso sí, siempre que no se alterasen los principios fundamentales que regían la feminidad: la mujer no podía hacerse hombruna. Asimismo, sucedía con la chicas o los jóvenes americanas, sus deportes y sus juegos estaban acorde con los códigos disciplinares impuestos por el patriarcado de la masculinidad y la heterosexualidad.

Por todo ello, no es de extrañar que en pleno siglo XXI tome fuerza la propuesta de una educación física crítica de resistencia, que es aquella que plantea la subversión del modelo hegemónico burgués que hoy se tiñe de neoconservadurismo y neoliberalismo (Beltrán-Carrillo \& Devís-Devís, 2019). Por lo tanto, rechaza todo lo que se mueva en el entorno de las nuevas tendencias, del consumo por el consumo, del patriarcado, de los desequilibrios sociales, de las violencias simbólicas... De este modo la «Educación física y moral» que citó el valenciano Amorós -de la heterosexualidad normativa burguesa-, hoy se enfrenta al paradigma de una pedagogía contra-sexual (Preciado, 2002). Y tampoco hay que especular con la educación física de casino-crossfit, paleotrining, parkour...-. Hay que ser cons- 
cientes, de este modo, que, hasta el presente, el capital corporal es uno de los principales bienes de consumo y que el dispositivo deportivo -punta de lanza del neoliberalismoatenta contra la misma infancia (Torrebadella-Flix y Domínguez, 2018).

Todo lo que surge contra el sistema es absorbido por el sistema y todo se vende - y se convierte en un instrumento más del sistema-. Aquí, como cita el profesor Miguel Vicente (2016, p. 79), conviene la invención de propuestas «orientadas por el interés crítico; es decir, hacia los éxitos emancipadores, racionalmente y voluntariamente asumidos por el alumnado». Sobre estos principios debería fundamentarse la nueva educación física-NEF-; en eso estamos convencidos en que no hay que pervertir el juego educativo. Sí, en este sentido, deberíamos ser críticos sobre la acción (pedagógica o demagógica) de gamificar la educación y, seguramente, oponernos a la obligación de jugar (Brasó \& Torrebadella, 2017) -y menos sin analizar las propuestas gamificadas reales y democráticas olvidadas de inicios del siglo XX (Brasó, 2018a; Brasó \& Torrebadella, 2018; Torrebadella \& Brasó, 2019)-. Ya no es necesario, si queremos hacer de la educación una práctica democrática y libre, perpetuar el naturalismo roussoniano, no juguemos más con la plastilina, dejemos de moldear al niño como la cera, dejemos de infantilizar la niñez, pero salvémosla de este entorno depredador, facilitémosle el pensamiento Krítico racional para cuestionar el mundo, si es necesario para desobedecer, para mostrar la indisciplina al adulto, para infringir las normas y para dar el giro necesario a los códigos disciplinares de una asignatura o materia todavía amordaza a un pasado oscuro del que no se ha liberado. Así es, demos razones al alumnado para ser único y hacerlo tan especialmente valioso que se sienta interesado por sus aprendizajes para ejercer una responsabilidad social plena.

Como bien indica Martínez Baena (2015), el momento de globalización e incertidumbre hace que la Educación Física tenga que comprometerse ante los nuevos retos del siglo XXI. Si como cita este autor, «la alternativa metodológica» pasa pues por el «intentar hacer los alumnos y alumnas futuros ciudadanos y ciudadanas con altos índices de moralidad» (Martínez Baena, 2015, p. 55) ¿dónde dejamos la motricidad? Todos conocemos jóvenes que son muy buenas personas, pero completamente desafortunados en su motricidad, situación que viene dada también por el déficit de una educación física sostenible con la diversidad. Hoy como en el pasado, la educación física es cómplice del poder dominante: neoliberal-neoconservador. Hoy hacemos de víctimas y a la vez, somos verdugos, sí, de aquí no se va nadie ¿no es absurda la educación? El profesor de educación física si tiene que ser moral, antes debería ser democrático y esto quiere decir, para que quede bien claro, que no debería ser de derechas, no debería ser católico, no debería ser monárquico, no debería ser nacionalista y no le debería gustar el fútbol, ni ningún otro deporte de casino cuya genealogía provenga del poder y la dominación. Por eso, también sucede que la educación física y el deporte tienen en las ciencias sociales un «lado oscuro» que no interesa conocer, que no interesa investigar, que no interesa divulgar (Barba, GonzálezCalvo \& Barba-Martín, 2014), vamos que no interesa que entre en la filosofía, como dirían los colegas Fernández Liria,
García Fernández y Galindo Fernández (2017).

La solución estaría en una pedagogía diferente -opuesta al populismo pedagógico (Sánchez Tortosa, 2018)- que se amparase nuevamente con la filosofía y no con la racionalidad tecnológica neoliberal (Vilanou, 2000), que se centrase en reconocer en nosotros los defectos de los Otros; en aceptar que los Otros forman también parte de nosotros, de nuestros miedos, y es por eso por lo que los negamos, porque no deseamos reconocer que hubiéramos podido ser como Ellos. En esta metafísica se encuentran otras alternativas de acción (Devís, Fuentes \& Sparkes, 2005; López Pérez, Manrique \& Monjas, 2016) y, además, las propuestas hacia las pedagogías sensibles y trans (Planella, 2009, 2015, 2017; Planella \& Pie, 2017), que son formas de comprender y activar actitudes disidentes y de superación con el lastre histórico y burgués que definió nuestras corporalidades modernas (Águila \& López, 2019).

Por lo tanto, pensamos que a partir de una didáctica de la contextualización crítica, las dinámicas de las CDR pueden formar parte de la enseñanza de la educación física (Vicente, 2016), puesto que son los intereses colectivos compartidos por los propios alumnos que ponen en juego proyectos alternativos de denuncia social contra los abusos de poder y las normas sociales o jurídicas injustas y que se han construido silenciosamente a lo largo de la historia en detrimento de las libertades personales y públicas. Las CDR responden pues, a una praxis de des-disciplinarización de la educación física (Vicente, 2016); surgen del conocimiento reflexivo con el pasado y de su análisis con el objeto de identificar un pensamiento krítico que se materialice en acción contra el poder hegemónico y que estimule en el alumnado una conciencia emancipadora y de responsabilidad social.

\section{A modo de conclusión}

El «corneball» era pues un juego pensado, como tantos otros, para mantener la heterosexualidad. Era un juego de niñas -el bajo contacto físico entre jugadores era uno de los hechos principales para que el sexo femenino pudiese jugar-, como así se aprecia perfectamente en el gráfico que proporciona Hernández Coronado (1932) [figura 1]. En sí, tenía la capacidad de que las niñas jugaran en grupo, de forma asociativa y con fair-play... es decir, tenía incorporado en la lógica interna del juego el dispositivo social que contribuye a proteger la feminidad de la mujer, como así lo ha estado haciendo durante décadas el netball en Australia (Tagg, 2016).

Por todo ello, pensamos que la revisión de los libros de Bancroft (1909) y de Jentzer (1921), es más que necesaria. Y es que introducir juegos alternativos a los convencionales y renovar o actualizar el repertorio de juegos es en sí un modo de hacer pedagogía crítica. Además, estos juegos pueden ser adaptados y modificados posibilitando que el alumnado descubra e interprete el juego, que explore sus posibilidades de forma autónoma y que se lo apropie como proyecto colectivo (Brasó \& Torrebadella, 2016).

La educación física ha servido siempre para preservar intereses políticos - liberales, conservadores, de derechas o de izquierdas-. Hoy, son estos intereses los que juegan y se reequilibran mutuamente en el universo de las postverdades 
y de los caóticos desconciertos del mundo globalizado: neoconservadurismo y neoliberalismo se entrelazan cómplices en las desigualdades sociales, en los desequilibrios biológicos y ambientales y en las crisis de identidad personales.

Si queremos que la educación física entre en el campo de los valores sociales postmodernos y de la moral o responsabilidad social, hoy no se puede prescindir del pensamiento krítico y del modelo de las CDR que proponemos. Solamente entonces, si somos capaces de transformar el giro didáctico-sofisticado (o demagógico) en giro ideológicodemocrático, estaremos en disposición de superar las comodidades y complicidades que nos enlazan con la contrariedad de un pasado idealista y totalitario; solamente entonces podrá surgir una NEF verdaderamente diferente y que avance hacia la emancipación social de personas y comunidades.

Apostamos así por estas pedagogías (más) humanas, críticas y sensibles, en las que el cuerpo no es un simple instrumento a las manos de una clase dominante, sino que se convierte en una herramienta para hacer mejores ciudadanos, implicados con el mundo, con el entorno, con la ciudad $\mathrm{y}$, por supuesto, con todas las personas -independientemente de su nivel económico, de sus orígenes, de sus pensamientos...

\section{Referencias}

Águila, C., \& López, J. (2019). Cuerpo, corporeidad y educación: una mirada reflexiva desde la Educación Física. Retos. Nuevas tendencias en Educación Física, Deportes y Recreación, 35, 413-421. Recuperado https:// recyt.fecyt.es/index.php/retos/article/view/62035

Ajuntament de Barcelona (1920). Els jardins dels infants. Barcelona: Ajuntament de Barcelona. Comissió de Cultura.

Althusser, L. (2005). La filosofía como arma de la revolución. Madrid: Siglo XXI.

Álvarez, L. (1927). Modern Lawn tennis. London: John Lane the Bodley Head Limited.

Amar, A., \& Jauffret, L. (1807). La gimnástica o escuela de la juventud, tratado elemental de juegos, de ejercicios considerados en razón de su utilidad física y moral. Madrid: Imp. Álvarez.

Andújar, I., \& Brasó, J. (2017). La lógica interna en Los Juegos de niños (1560) de Peter Brueghel. RICYDE. Revista Internacional de Ciencias del Deporte, 50, 426-441. https://doi.org/10.5232/ricyde2017.05008

Ayala, I., \& Salagaz, M. (2016). Gimnasia, Música y Patria: exhibiciones gimnásticas en el franquismo. El caso de los Festivales salesianos y el XIV Campeonato Nacional de Gimnasia Educativa. Retos. Nuevas tendencias en Educación Física, Deportes y Recreación, 30, 114-124. Recuperado de https://recyt.fecyt.es/index.php/retos/ article/view/49026

Bancroft, J. H. (1909). Games for the playground, home, school and gymnasium: New York: Macmillan.

Barba, J., González-Calvo, G., \& Barba-Martín, R. (2014). Que la fuerza esté contigo: desvelar el lado oscuro de la investigación en educación. Magis, Revista Internacional de Investigación en Educación, 7(14). 125-140. https://doi.org/10.11144/Javeriana.M7-14.QLFE

Bauman, Z. (2017). Modernidad Líquida. Madrid: Fondo de Cultura Económica.
Beltrán-Carrillo, V., \& Devís-Devís, J. (2019). El pensamiento del alumnado inactivo sobre sus experiencias negativas en educación física: los discursos del rendimiento, salutismo y masculinidad hegemónica. RICYDE. Revista Internacional de Ciencias del Deporte, 15(55), 20-34. https://doi.org/10.5232/ricyde2019.05502

Blanco, R. (1919, abril). De Re Pedagogica. Del juego y su importancia como medio de educación integral. Unión Ibero-Americana, 10, p. 20-21.

Bourdieu, P., \& Passeron, J. C. (1996). La reproducción. Elementos para una teoría del sistema de enseñanza. Barcelona: Laia.

Brasó, J. (2016). Los inicios de la mujer en la práctica del ajedrez en España (1922-1935). Investigaciones Feministas, 7(2), 331-355. https://doi.org/10.5209/INFE.51750

Brasó, J. (2018a). Pere Vergés: escuela y gamificación a principioss del s. XX. Apunts. Educación Física y Deportes, 183, 20-87. http://dx.doi.org/10.5672/apunts.20140983.es.(2018/3).133.02

Brasó, J. (2018b). Higienisme, educació i colònies escolars al voltant de 1918. Jornada de Pensament Pedagògic Avançat: Reflexió Sistemàtica. 4, de juliol. Universitat de Barcelona: Departament de Teoria i Història de l’Educació.

Brasó, J., \& Torrebadella, X. (2015a). Anàlisi i classificació dels jocs de la infància de Joan Amades en funció de la seva lógica interna i del gènere dels practicants (16741947). REIRE. Revista d'Innovació i Recerca en Educació, 8(2), 18-42. Recuperado http://revistes.ub.edu/ index.php/REIRE/article/view/reire2015.8.2822

Brasó, J., \& Collell, X. (2016). El joc popular de la xarranca. Estudi a través dels llibres i del folklore català. Possibles aplicacions en l'àmbit escolar. REIRE. Revista d'Innovació i Recerca en Educació 9(2), 82-105. Recuperado http://revistes.ub.edu/index.php/REIRE/article/ view/reire2016.9.2926

Brasó, J., \& Torrebadella, X. (2014). El joc del 'rescat' a Catalunya. Un projecte educatiu a l'Escola del Mar de Pere Vergés. Temps d'Educació, 47, 191-212. Recuperado https://www.raco.cat/index.php/TempsEducacio/ article/view/286025

Brasó, J., \& Torrebadella, X. (2015b). «El marro», un juego tradicional y popular en la educación física española (18071936). Revista Complutense de Educación, 26(3), 697719. https://doi.org/10.5209/rev_RCED.2015.v26.n3.44680

Brasó, J., \& Torrebadella, X. (2016). Investigación-acción y método de proyectos en educación física: organización de un torneo de marro. Estudios Pedagógicos, 42(2), 2137. https://dx.doi.org/10.4067/S0718-07052016000200002

Brasó, J., \& Torrebadella, X. (2017). ¿Por qué nos hacen jugar en la escuela? Reflexiones pedagógicas para (¿criticar?) entender la enseñanza actual. En R. Mínguez \& E. Romero (Coord.), CITE. XIV Congreso de Teoría de la Educación. Murcia 21 y 23 de noviembre de 2017. La educación ante los retos de una nueva ciudadanía (pp. 541549). Murcia: Universidad de Murcia.

Brasó, J., y Torrebadella, X. (2018). Reflexiones para (re)formular la educación física crítica. Revista Internacional de Medicina y Ciencias de la Actividad Física y el Deporte, 18(71), 441-462. http://dx.doi.org/10.15366/ rimcafd2018.71.003

Caspistegui, F. J. (2004). La resbaladiza arista de un monte erguida sobre dos abismos: mujer y deporte en España. 
Memoria y Civilización, 7, 129-174.

Chomsky, N. (2005). L'educació. Barcelona: Columna.

Cuesta, R. (2002). El código disciplinar de la historia escolar en España: Algunas idees para la explicación de la sociogénesis de una materia de enseñanza. Encounters on Education, 3, 27-41.

Cuesta, R. (2003). Campo profesional, formación del profesorado y apuntes de didáctica crítica para tiempos de desolación. Didáctica de las Ciencias Sociales, 17, 323.

Cuesta, R. (2006). La escuela y el huracán del progreso ¿por qué todavía es hoy necesaria una crítica histórica de la escolarización de masas? Indaga. Revista Internacional de Ciencias Sociales y Humanas, 4, 53-94.

Cuesta, R. (2007). Los deberes en la memoria de la educación. Madrid: Octaedro.

De Castro Les, V. (1924, julio). La pequeña Olimpiada en el Instituto-Escuela. Gran Vida, p. 198-200.

De Luis, F. (2006). Magisteri i sindicalisme a Catalunya. La Federació Catalana de Treballadors de l'Ensenyament. Des del seu origen a la Guerra Civil. Barcelona: Serbal.

De Puelles, M. (2017). Política educativa en perspectiva histórica. Textos escogidos. Madrid: Biblioteca Nueva.

Devís, J., Fuentes, J., \& Sparkes, A. C. (2005). ¿Qué permanece oculto del currículum oculto? Las identidades de género y de sexualidad en la educación física. Revista iberoamericana de educación, 39, 73-90.

Eleizegui, J. (1925). Los Juegos de la Infancia. Barcelona: Sociedad General de Publicaciones.

Enkvist, I. (2016). El complejo oficio del profesor. Madrid: Fineo.

Fernández Liria C., García Fernández, O., \& Galindo Fernández, E. (2017). Escuela o Barbarie. Entre el neoliberalismo salvaje y el delirio de la izquierda. Madrid: Akal.

Gambarotta, E. M., \& Galak, E. L. (2012). Educación de los cuerpos: crítica de la reproducción social y de las potencialidades de su transformación en el marco de la Educación Física. Estudios pedagógicos (Valdivia) 38. Especial, 67-87.

García García, J. (2015). El origen del deporte femenino en España. Madrid: Jorge García García.

Gulick, H. L. (1918). La educación física por medio del ejercicio muscular. Barcelona: Manuel Marín editor.

Hernández Coronado, R. (1932, 26 de noviembre). Los juegos en educación física. Luz, p. 14.

Jentzer, K. (1921). Juegos educativos al aire libre y en casa. Madrid: Ed. Francisco Beltrán Librería Española y Extranjera.

Juegos y gimnasia para niñas (1922, 15 de febrero). La escuela Moderna (suplemento), p. 208.

Junta Ampliación de Estudios e Investigaciones Científicas (1922). Memoria correspondiente a los años 1920 y 1921. Madrid: JAE.

Justribó, D. (2014). Feminitat, esport, cultura: pioneres de l'atletisme català (1921-1938). Barcelona: Daniel Justribó.

Llorens, M., \& Torrebadella, X. (2017). La gimnástica o escuela de la juventud (1807): primer libro de educación física escolar y génesis de un discurso pedagógico. Revista de Investigación en Educación, 15(2), 122-139.

López, V.; Pérez, D.; Manrique, J., \& Monjas, R. (2016). Los retos de la Educación Física en el Siglo XXI. Retos. Nuevas tendencias en Educación Física, Deportes y Re- creación, 29, 182-187. Disponible en: https:// recyt.fecyt.es/index.php/retos/article/view/42552/25499

López Villar, C. (2017). Pioneras do deporte en Galicia. Coruña: Deputación da Coruña.

López-Villar, C. (2014). The Beginnings of Hockey in 1930sGalicia (Spain): A Female Phenomenon. The International Journal of the History of Sport, 31(9), 11331157. https://doi.org/10.1080/09523367.2014.882911

Luzuriaga, L. (1917, 31 de diciembre). Las grandes reformas escolares. Boletín de la Institución Libre de Enseñanza, 693, 361-363.

Luzuriaga, L. (1918a, 31 de enero). Las grandes reformas escolares. Boletín de la Institución Libre de Enseñanza, 694, 15-17.

Luzuriaga, L. (1919, 23 de junio). La pedagogía en las grandes ciudades. Jardines y campos de juegos para niños. El Sol (Madrid), p. 12.

Manjón, A. (1910). Las escuelas laicas. Barcelona: Herederos de Juan Gili.

Martínez Baena, A. C. (2015). Globalización e incertidumbre valorativa: nuevos retos de la educación física del siglo XXI. Tándem. Didáctica de la Educación Física, 50, 49-58.

Martínez Navarro, A. (1988). Educación corporal en el modelo pedagógico propuesto por la Junta de Ampliación de Estudios Científicos. En J. M. Sánchez Ron (Coord.), 19071987. La Junta para Ampliación de Estudios e Investigaciones Científicas 80 años después. Vol. II (pp. 239256). Madrid: CSIC.

Mosse, G. (2000). La imagen del hombre. La creación de la moderna masculinidad. Madrid: Talasa.

Mosse, G. (2005). La nacionalización de las masas. Simbolismo político y movimiento de masas en Alemania desde las Guerras Napoleónicas al Tercer Reich. Madrid: Marcial Pons.

Murga, I. (2009). Escenografía de la danza en la Edad de Plata (1916-1936). Madrid: CSIC.

Ontañón, E. (1988). Instituto-Escuela, experiencia educativa de la JAE. En J. M. Sánchez Ron (Coord.), 1907-1987. La Junta para Ampliación de Estudios e Investigaciones Científicas 80 años después. Vol. II (pp. 201-238). Madrid: CSIC.

Palacios Bañuelos, L. (1988). Instituto-Escuela: historia de una renovación educativa. Madrid: Ministerio de Educación.

Parlebas, P. (2001). Juegos, deporte y sociedad. Léxico de praxiología motriz. Barcelona: Paidotribo.

Planella, J. (2009). Ser Educador. Entre Pedagogía y Nomadismo. Barcelona: UOC.

Planella, J. (2017). Pedagogías sensibles. Sabores y saberes del cuerpo y la educación. Barcelona: Universidad de Barcelona.

Planella, J., \& Pié, A. (coord.) (2015). Políticas, prácticas y pedagógicas TRANS. Barcelona: UOC.

Preciado, B. (2002). Manifiesto contra-sexual. Madrid: Opera Prima.

Pujadas, X. (2011). Del barrio al estadio. Deporte, mujeres y clases Populares en la segunda República, 1931-1936. En X. Pujadas (coord.), Atletas y ciudadanos. Historia social del deporte en España, 1870-2010 (pp. 125-167). Madrid: Alianza Editorial.

Pulido, A. (1906, 22 de febrero). El corro de las niñas. El Mundo Deportivo, p. 1. 
Ramírez Aisa, E. (1994). La formación inicial del profesorado en el Instituto-Escuela: 1918-1936. Espacio Tiempo y Forma. Serie V, Historia Contemporánea, 7, 563-584.

Ramos, I. (2017). Margot Moles, la gran atleta republicana. Madrid: Libros. Com.

Sánchez-Ribera, F., \& Torrebadella-Flix, X. (2018). La introducción del netball en la educación primaria. Hacia una didáctica crítica de las prácticas deportivas de género. EmásF, 9(53), 96117.

Sánchez Tortosa, J. (2018). El culto pedagógico. Crítica al populismo educativo. Madrid: Akal.

Scharagrodsky, P., Manolakis, L., \& Gosende, E. (2003). La educación física en los manuales y textos escolares (1880-1930). GénEros, 11(31), 32-46.

Soler, J. (2009). Influència i presència de l'Institut Rousseau de Ginebra en la pedagogia catalana del primer terç del segle XX. Temps d'Educació, 11(37), 11-38.

Soler, J. (2016). La escuela activa de Adolfo Ferrière en la pedagogía española e iberoamericana. En J. M. Hernández Díaz (coord.), Influencias suizas en la educación española e iberoamericana (pp. 69-82). Salamanca: Ediciones de la Universidad de Salamanca.

Soler, J., \& Vilanou, C. (2018). Giner y la renovación pedagógica en Cataluña. Entre la tradición liberal y la historia conceptual. En I. Vilafranca \& C. Vilanou (eds.), Giner i la Institución Libre de Enseñanza des de Catalunya. Cent anys després de la mort de Francisco Giner de los Ríos (1839-1915) (pp. 101-126). Barcelona: Universitat de Barcelona.

Tagg, B. (2016). Men's netball or gender-neutral netball? International Review for the Sociology of Sport, 51(3), 314331.

Tangil (1922a, 15 de febrero). 11 de febrero de 1922. Gaceta del 12 de febrero, La escuela Moderna (suplemento), p. 198.

Tangil (1922b, 8 de marzo). 27 de febrero de 1922. (Gaceta del 2 de marzo). La escuela Moderna (suplemento), p. 308.

Torrebadella-Flix, X. (2014). El push-ball en España. La historia de un deporte que no alcanzó carta de naturaleza (1897-1936). Agon. International Journal Sport o Sciences, 4(2), 71-84. Recuperado http://agonjournal.com/wp-content/uploads/2015/ 04/4_Torrebadella_4_2_AGON_71_841.pdf [consulta el 31 de enero de 2019].

Torrebadella-Flix, X. (2016). La bibliografía gimnástica y deportiva de la educación física en el ejército español (1808-1919). Textos en contexto social. Revista Universitaria de Historia Militar, 5(9), 173-192. Recuperado http://ruhm.es/index.php/ RUHM/article/view/182

Torrebadella-Flix, X., \& Brasó, J. (2017). Barcelona y el problema de la educación física en la primera enseñanza a principios del siglo XX. Las Escuelas Catalanas del Distrito VI. Revista Brasileira de História da Educação, 17(2), p. 135-173. http:/ /dx.doi.org/10.4025/rbhe.v17, n2.915.

Torrebadella-Flix, X., \& Domínguez, J.A. (2018). El deporte en la educación física escolar. La revisión histórica de una crítica inacabada. Retos: Nuevas Tendencias de la Educación Física y el Deporte, 34, 403-411. Recuperado de https://recyt.fecyt.es/ index.php/retos/article/view/57963/39905

Torrebadella-Flix, X., \& Ticó, J. (2014). Notas para la historia del centenario del baloncesto español. Un deporte escolar y popular para ambos sexos (1897-1938). E-Balonmano.com: Revista de Ciencias del Deporte, 10(3), 177-198. Recuperado http:/ /www.e-balonmano.com/ojs/index.php/revista/article/view/158

Torrebadella-Flix, X., \& Vicente-Pedraz, M. (2017). En torno a los orígenes del fútbol como deporte escolar en España (18831936). De moda recreativa a dispositivo disciplinario. Educa- ción Física y Ciencia, 19(1), e018. https://doi.org/10.24215/ $23142561 \mathrm{e} 018$.

Torrebadella, X. (2012). El deporte contra la educación física. Un siglo de discusión pedagógica y doctrinal en la educación contemporánea. Movimiento humano, 4, 73-98.

Torrebadella, X. (2013a). Anotaciones al balonmano en el contexto histórico del deporte en España (1900-1939). e-balonmano. Revista de Ciencias del Deporte, 9(2), 115-134.

Torrebadella, X. (2013b). La aportación bibliográfica de Joan Bardina a la educación física moderna (1911-1939). Cabás, 9 , $1-22$.

Torrebadella, X. (2014a). La influencia de la profesión médica en la educación física española del siglo XIX: Análisis social del Manual popular de gimnasia de sala, médica e higiénica del Dr. Schreber. Cultura, Ciencia y Deporte, 9(26), 163-176. http:// dx.doi.org/10.12800/ccd.v9i26.434

Torrebadella, X. (2014b). Los apóstoles de la educación física. Trece semblanzas profesionales en la educación física española contemporánea. Revista Española de Educación Física, 406, 57-76. Recuperado http://www.reefd.es/index.php/reefd/article/ view/26

Torrebadella, X. (2018a). En torno a los orígenes del voleibol en España en el espacio escolar, civil y militar (1920-1936). RICYDE. Revista Internacional de Ciencias del Deporte, 56, 187-208. https://doi.org/10.5232/ricyde2019.05605

Torrebadella, X. (2018b). «Ludos pro Patria»: Aprender a disparar para salvar la nación. La Razón Histórica. Revista hispanoamericana de Historia de las Ideas, 40, 133-164. Recuperado https://www.revistalarazonhistorica.com/40-9/

Torrebadella, X., \& Brasó, J. (2019). Los juegos corporales en la educación física del siglo XIX como preludio al deporte moderno en España. Ciencia, Cultura y Deporte, 14(41), 165-177. http://dx.doi.org/10.12800/ccd.v14i41.1276

Vázquez Ramil, R. (2012). Mujeres y educación en la España contemporánea. La Institución Libre de Enseñanza y la Residencia de señoritas de Madrid. Madrid: Akal.

Vicente-Pedraz, M., \& Brozas-Polo, M. (2017). El triunfo de la regularidad: gimnasia higiénica contra acrobacia en la configuración física escolar en la segunda mitad del siglo XIX. Revista Brasilera do Sporte. 39(1), 49-55. http://dx.doi.org/10.1016/ j.rbce.2015.10.006

Vicente, M. (2016). Bases para una didáctica crítica de la educación física. Apunts. Educación Física y Deportes, 123, 76-85.

Vilanou, C. (2000). Pedagogia al deixant del segle XX. Temps d'Educació, 24, 13-60.

Vilanou, C., De la Arada, R., \& Turró, G. (2013). Lilí Álvarez, tenista e intelectual: entre el eterno femenino y la mujer eterna. Ars Brevis, 19, 216-250.

\section{(Nota)}

Alice Gordon Gulick (1847-1903) se instala en Santander en 1877 y pone inicio a la creación de una escuela para chicas, que deseaba ser el Mount Holyoke College en España y en 1881 junto a su marido William Hooper Gulick fundó en San Sebastián el Instituto Internacional o Colegio Norteamericano. El conflicto bélico hizo que entre 1898 y 1903 viviese en Estados Unidos, hasta que se trasladó en Madrid en la calle Fortuny 53 en donde instaló el International Institute for Girls, que tiempo más tarde también ocuparía el nuevo edificio de la calle Miguel Ángel $n^{\circ} 8$ 